\title{
Treatment of Anterior Dental Crossbite Using Bonded Resin-Composite Slopes: Case Reports
}

\author{
Sule Bayrak ${ }^{a}$ \\ Emine Sen Tunc ${ }^{a}$
}

\begin{abstract}
Anterior crossbite is the term used to describe an abnormal labiolingual relationship between one or more maxillary and mandibular incisor teeth. Different techniques have been used to correct anterior crossbite. This paper describes the use of bonded resin-composite slopes for the management of anterior crossbite in children in early mixed dentition.

In each of the cases presented here, dental crossbite was corrected by applying a 3-4 mm bonded resin-composite slope to the incisal edge of the mandibular incisor with an angle $45^{\circ}$ to the longitudinal axis of the tooth. Correction was achieved within 1-2 weeks with no damage to either the tooth or the marginal periodontal tissue. The procedure is a simple and effective method for treating anterior dental crossbite. (Eur J Dent 2008;2:303-307)
\end{abstract}

Key words: Anterior crossbite; Bonded-resin-composite slopes; Children; Mixed dentition.

\section{INTRODUCTION}

Anterior crossbite is defined as a malocclusion resulting from the lingual positioning of the maxillary anterior teeth in relationship to the mandibular anterior teeth. ${ }^{1}$ Dental crossbite involves localized tipping of a tooth or teeth and does not involve basal bone. ${ }^{2}$ Patients with anterior dental crossbite will show a normal anterior-posterior skeletal relationship with a smooth path of mandibular closure into an Angle Class I relationship and coincident centric occlusion and centric relation. ${ }^{3}$

a Assistant Professor, Department of Pediatric Dentistry, Faculty of Dentistry, University of Ondokuz Mayis, Samsun, Turkey.

- Corresponding author: Sule Bayrak Department of Pediatric Dentistry, Faculty of Dentistry, University of Ondokuz Mayis, 55139. Kurupelit, Samsun, Turkey.

Phone: $+903623121919 / 3365$

Fax: +90 362457603

E-mail: suleb76ayahoo.com
Anterior dental crossbite has a reported incidence of $4-5 \%$ and usually becomes evident during the early mixed-dentition phase..$^{4-7} \mathrm{~A}$ variety of factors have been reported to cause anterior dental crossbite, including a lingual eruption path of the maxillary anterior incisors; trauma to the primary incisor resulting in lingual displacement of the permanent tooth germ; supernumerary anterior teeth; an over-retained necrotic or pulpless deciduous tooth or root; odontomas; crowding in the incisor region; inadequate arch length; and a habit of biting the upper lip. ${ }^{3-9}$

Various treatment methods have been proposed to correct anterior dental crossbite, such as tongue blades, reversed stainless steel crowns, fixed acrylic planes, bonded resin-composite slopes and removable acrylic appliances with finger springs. $3,9-11$

This article documents 3 cases in which 
anterior dental crossbite were successfully corrected using bonded resin-composite slopes.

\section{CASE REPORTS}

\section{Technique}

All of the cases reported here were in early mixed dentition and had Class I molar and canine relationships. In every case there was sufficient mesiodistal distance to achieve labial movement of the maxillary tooth.

Medical histories of the children were noncontributory. Following clinical and radiographic examinations, the decision was made to create a bonded resin-composite slope. Parents of each of the patients gave their written informed consent for the treatment. The labial surface of the occluding lower incisor or incisors were etched with $37 \%$ phosphoric acid (Etch37 with BAC, Bisco, USAl for 15 seconds rinsed and dried. An adhesive system (Gluma One Bond, Heraus Kulzer, Germanyl was applied and cured for $20 \mathrm{~s}$ using a visible light unit (HILUX, Benlioglu Dental, Ankara, Turkey). Composite resin (Charisma, Heraus Kulzer, Germany) was formed into an inclined slope and applied to the labial surface of each incisor to create a slope of $3-4 \mathrm{~mm}$ in thickness at a $45^{\circ}$ angle to the longitudinal axis of the tooth. The composite was cured and polished using a polishing disc. The occlusion was checked to confirm that the treated incisors represented the only points of contact between the arches. (Typically, posterior teeth do not contact immediately following slope placement; however, normal posterior occlusion is re-established as soon as the maxillary incisor is displaced labially.)

The children were motivated to maintain good oral hygiene and recalled after 1 week to clinically evaluate the treatment progress and periodontal health of the anterior teeth. Crossbite correction was completed in 1-2 weeks. Following correction, the resin slope was removed with a diamond bur at low speed, the enamel surface was polished using aluminum oxide finishing discs, and topical fluoride was applied.

\section{Case 1}

An 8-year-old boy visited the pediatric dental clinic for routine control. Intraoral examination revealed a maxillary left central incisor in crossbite (Figure 1a). A composite slope was bonded to the mandibular left central and lateral incisors and remained in place for 1 week (Figure $1 \mathrm{~b}$ and $1 \mathrm{c}$.

Case 2

A 9-year-old boy was referred to the pediatric dental clinic. The parents' chief complaint was anterior crossbite. Intraoral examination revealed the permanent maxillary right and left central incisors were in crossbite (Figure 2a). The crossbite was corrected in two weeks (Figure $2 \mathrm{~b}$ and $2 \mathrm{c}$.

\section{Case 3}

A 7-year-old girl presented at our clinic with a maxillary right central incisor in crossbite with the mandibular central and lateral incisors (Figure 3a). A bonded resin-composite slope was applied, and the crossbite was corrected in 1 week (Figure $3 b$ and $3 c$ ).

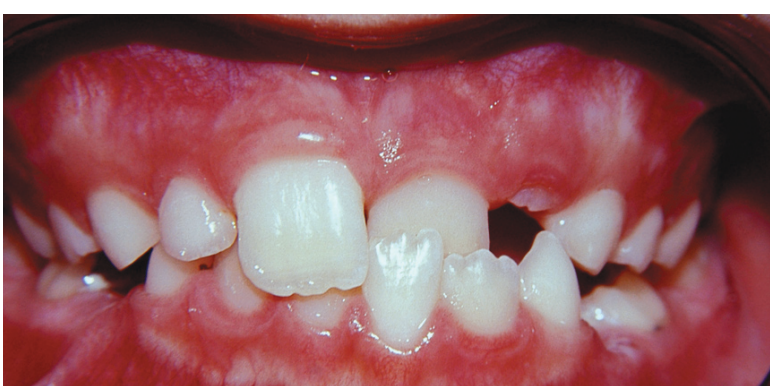

Figure 1a. An 8-year-old boy with crossbite of the maxillary left central incisor.

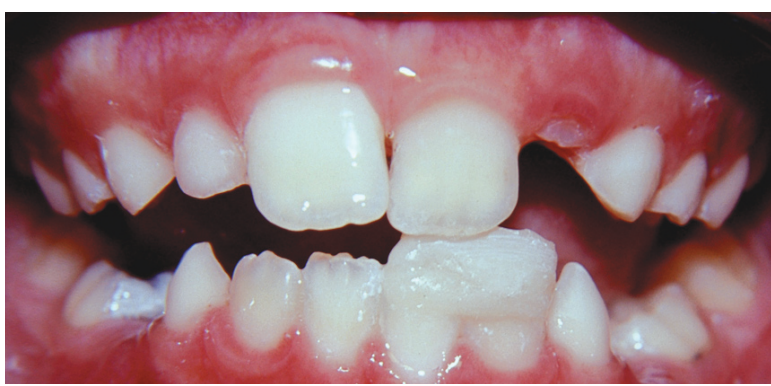

Figure 1b. Frontal view of bonded composite resin slope in occlusion.

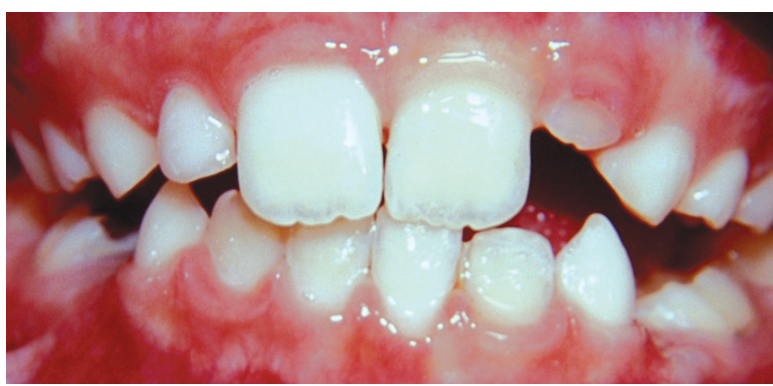

Figure 1c. Posttreatment frontal view of the maxillary left central incisor. 


\section{DISCUSSION}

One of the chief objectives of pediatric dentistry is to guide the developing dentition to a state of normalcy in line with the stage of oral-facial growth and development. ${ }^{12}$ The period of mixed dentition offers the greatest opportunity for occlusal guidance and interception of malocclusion..$^{13}$ If delayed to a later stage of maturity, treatment may become more complicated..$^{14}$

Anterior dental crossbite requires early and immediate treatment to prevent abnormal enamel abrasion, anterior teeth mobility and fracture, periodontal pathosis and temporomandibular joint disturbance. ${ }^{8,9,15-19}$ The main goal of treatment is to tip the affected maxillary tooth or teeth labially to the point where a stable overbite relationship exists. ${ }^{19}$ Relapse is usually prevented by the normal overjet/overbite relationship that is achieved. ${ }^{20}$

Different techniques have been used to

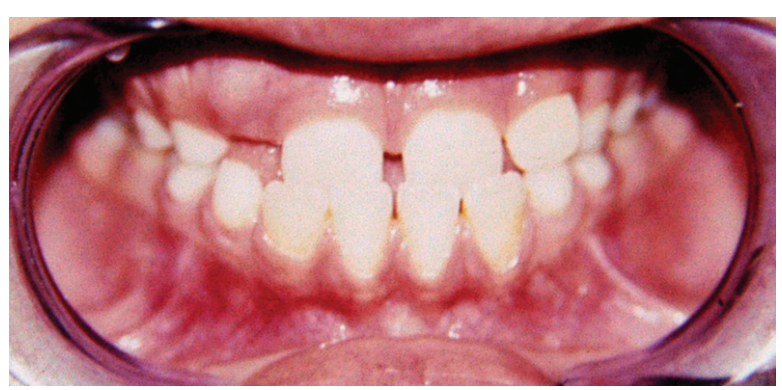

Figure 2a. A 9-year-old boy with crossbite of the maxillary right and left central incisors.

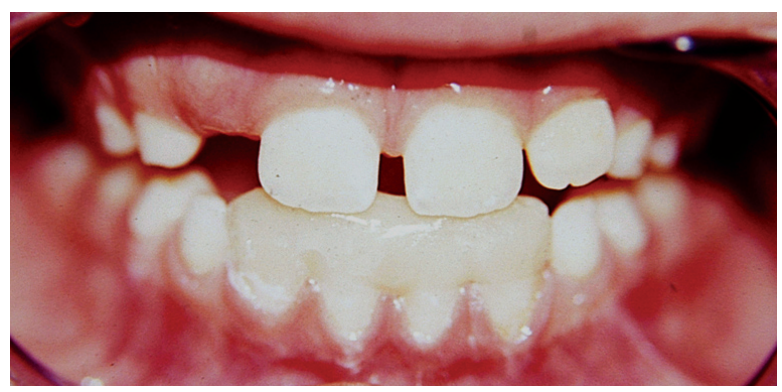

Figure 2b. Frontal view of bonded composite resin slope in occlusion.

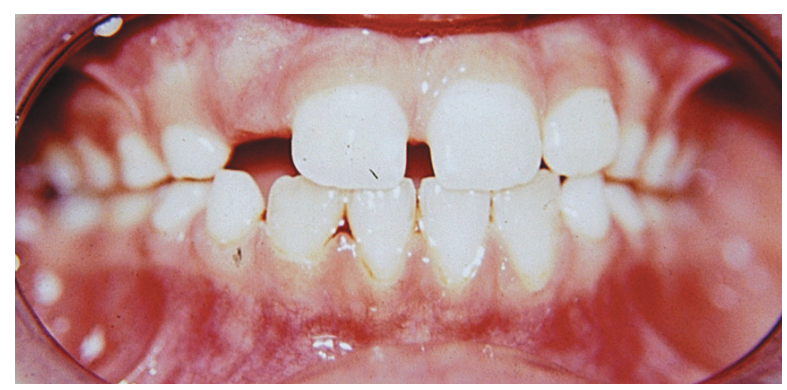

Figure 2c. Posttreatment frontal view of the central incisors. correct anterior dental crossbite. The reversed stainless steel crown is a well-known method for correcting anterior dental cross-bite. ${ }^{21,22}$ The chief disadvantage of this method is the difficulty in adapting a preformed crown to fit the tooth in crossbite. ${ }^{21}$ Furthermore, the reversed stainless steel crown is an unaesthetic treatment that is often rejected by children and their relatives. ${ }^{18,22}$ The tongue blade can also be an effective method of treatment during the early phase of eruption; however, it requires total cooperation from the patient, which in most cases is difficult to obtain. ${ }^{10}$ Similarly, the use of removable acrylic appliances with posterior bite opening platforms and anterior finger springs for labial tipping of maxillary teeth ${ }^{9,16,19}$ also requires patient cooperation. ${ }^{1 / 4} \mathrm{~A}$ lower acrylic inclined-bite-plane is another effective treatment method; however, it requires a laboratory phase, which increases the price of treatment, and the cement used with

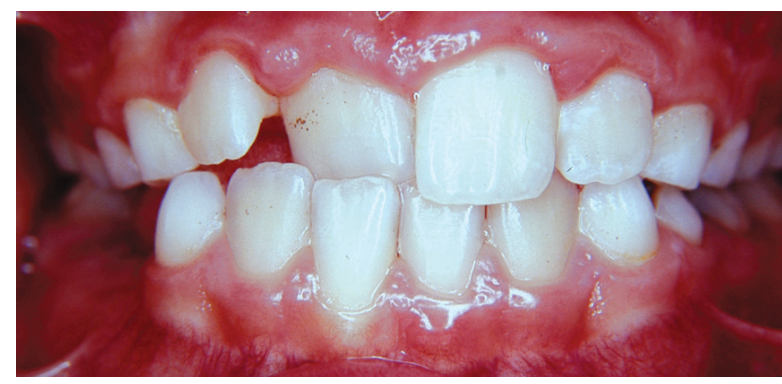

Figure 3a. A 7-year-old girl with crossbite of the maxillary right central incisor.

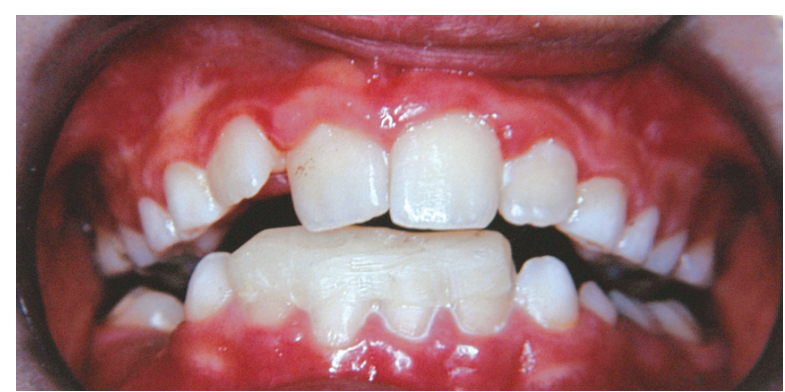

Figure 3b. Frontal view of bonded composite resin slope in occlusion.

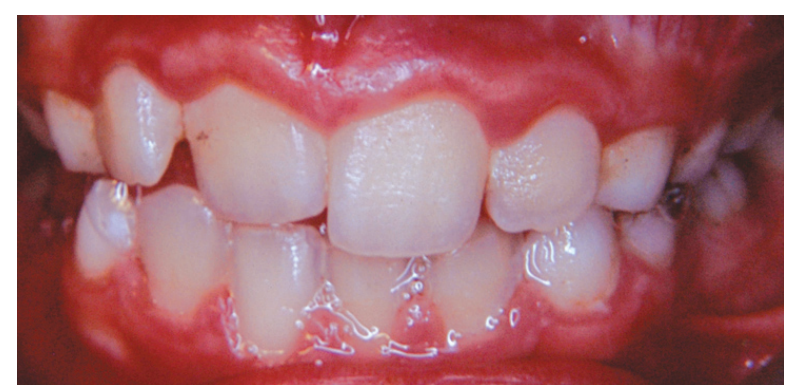

Figure 3c. Posttreatment frontal view of the maxillary right central incisor. 
this type of appliance may cause gingivitis. ${ }^{23,24}$

Because of the disadvantages of the methods mentioned above, the cases reported here were all treated using a bonded resin-composite slope. This method represents a safe, quick, easy and esthetically acceptable alternative for the correction of anterior dental crossbite. The procedure is low-cost, involves no discomfort, and it can be completed in only a few visits to the clinic. Treatment time is short, since retention is achieved once the tooth is in the correct position, and it is also low-cost. 8,21

In all of the cases reported here, correction of anterior dental crossbite was observed within 1-2 weeks, with no damage to teeth or marginal periodontal tissue.

\section{CONCLUSIONS}

As demonstrated in these three cases, a bonded resin-composite slope is a simple and effective method for treating anterior dental crossbite.

\section{REFERENCES}

1. Tsai HH. Components of anterior crossbite in the primary dentition. ASDC J Dent Child 2001;68:27-32.

2. Marrison JT. Fundamentals of Pediatric Dentistry. 3rd ed. London: Quintessence Publishing Co, 1995:355.

3. Olsen CB. Anterior crossbite correction in uncooperative or disabled children. Case reports. Aust Dent J 1996;41:304309.

4. Major P, Glover K. Treatment of anterior cross-bites in the early mixed dentition. J Can Dent Assoc 1992;58:574-575.

5. Heikinheimo K, Salmi K, Myllarniemi S. Long-term evaluation of orthodontic diagnosis make at ages of 7 and 10 years. Eur J Orthod 1987;9:151-159.

6. Hannuksela A, Vaananen A. Predisposing factors for malocclusion in 7-year-old children with special reference to atopic diseases. Am J Orthod Dentofacial Orthop 1987;92:299-303.

7. Hannuksela A, Laurin A, Lehmus V, Kauri R. Treatment of cross-bite in the early mixed dentition. Pron Finn Dent Soc 1988;84:175-182.

8. Estreia F, Almerich J, Gascon F. Interceptive correction of anterior crossbite. J Clin Pediatr Dent 1991;15:157-159.

9. Valentine F, Howitt JW. Implications of early anterior crossbite correction. J Dent Child 1970;37:420-427.

10. Deam JA, McDonald RE, Avery DR. Managing the Developing Occlusion. In: McDonald RE (ed). Dentistry for the Child and Adolescent. $7^{\text {th }}$ ed. London; Mosby, 2000:677-741.
11. Vadiakas G, Viazis AD. Anterior crossbite correction in the early deciduous dentition. Am J Orthod Dentofacial Orthop 1992;102:160-162

12. al-Sehaibany F, White G. A three dimensional clinical approach for anterior crossbite treatment in early mixed dentition using an Ultrablock appliance: case report. J Clin Pediatr Dent 1998;23:1-8.

13. Kocadereli I. Early treatment of posterior and anterior crossbite in a child with bilaterally constricted maxilla: report of case. J Dent Child 1998;65:41-46.

14. Tse CS. Correction of single-tooth anterior crossbite. J Clin Orthod 1997;31:188.

15. Tobias MT, Album MM. Anterior crossbite correction on a cerebral palsy child. J Dent Child 1977;44:460-462.

16. Lee BD. Correction of crossbite. Dent Clin North Am 1978;22:647-668.

17. Payne RC, Mauller BH, Thomas HF. Anterior crossbite in the primary dentition. J Pedod 1981;5:281-294.

18. Sexton T, Croll TP. Anterior crossbite correction in the primary dentition using stainless steel crowns. J Dent Child 1983;50:117-120.

19. Jacobs SG. Teeth in crossbite: the role of removable appliances. Australian Dent J 1989;34:20-28.

20. Croll TP. Fixed inclined plane correction of anterior crossbite of the primary dentition. J Periodontics 1984;9:8497.

21. Croll TP. Correction of anterior tooth crossbite with bonded resin-composite slopes. Quintessence Int 1996;27:7-10.

22. Croll TP, Lieberman WH. Bonded compomer slope for anterior tooth crossbite correction. Pediatr Dent 1999;21:293-294.

23. Croll TP, Riesenberg RE. Anterior crossbite correction in the primary dentition using fixed inclined plane I. Quintessence Int 1988;1:847-853.

24. Croll TP, Riesenberg RE. Anterior crossbite correction in the primary dentition using fixed inclined plane II. Quintessence Int 1988;1:45-51. 